\begin{tabular}{|c|c|}
\hline \multirow{3}{*}{ 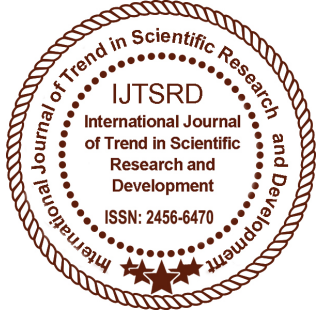 } & $\begin{array}{l}\text { International Journal of Trend in Scientific } \\
\text { Research and Development (IJTSRD) }\end{array}$ \\
\hline & International Open Access Journal \\
\hline & ISSN No: 2456 - 6470 | www.ijtsrd.com | Volume - 2 | Issue - 5 \\
\hline
\end{tabular}

\title{
An Efficient Image Processing based Security Technique using Raspberry Pi
}

\author{
Jimy Bazaz ${ }^{1}$, Abita Devi ${ }^{2}$ \\ ${ }^{1}$ M.Tech Scholar, Department of Electronics \& Communication Engineering, ${ }^{2}$ Assistant Professor \\ Panchkula Engineering College, Panchkula, Haryana, India
}

\begin{abstract}
Image processing is one of the latest and prominent fields of computing and plays a very important role in security also like Steganography. IOT is the latest and emerging technology and need for the modern life. The paper is about the mixture of the above technologies to make a very dynamic security approach that addresses number of issues. In my approach I am using Raspberry Pi with camera to capture images and send these images to another Raspberry Pi in encrypted format.
\end{abstract}

Keyword: IOT, Raspberry Pi

\section{INTRODUCTION}

Image processing is a method to perform some operations on an image, in order to get an enhanced image or to extract some useful information from it. It is a type of signal processing in which input is an image and output may be image or characteristics/features associated with that image. Nowadays, image processing and IOT are among rapidly growing technologies. The term "Things" in IOT refers to various IOT devices having unique identities and has capabilities to perform remote sensing, actuating and live monitoring of certain sorts of data. IOT devices are also enabled to have live exchange of data with other connected devices and applications either directly or indirectly, or collect data from other devices and process the data and send the data to various servers. Security is prime concern in modern computing like security of applications. My research is based on Raspberry Pi a computer with the size of a credit card, which was designed to promote the training on computer programming skills and the understanding of computer hardware in schools. Due to its size and accessibility in price, it was adopted by

users for projects that required more than a primary microcontroller. Raspberry pi has computer capabilities with a free operating system called Raspbian which is a version of Debi an and is optimized for the hardware components of the system. The system is capable of running wireless home speakers, a media centre for TVs, and personal web servers. It is a low-cost portable miniature computer which can play high-definition video. The following figure shows a functional block schematic of Raspberry Pi.

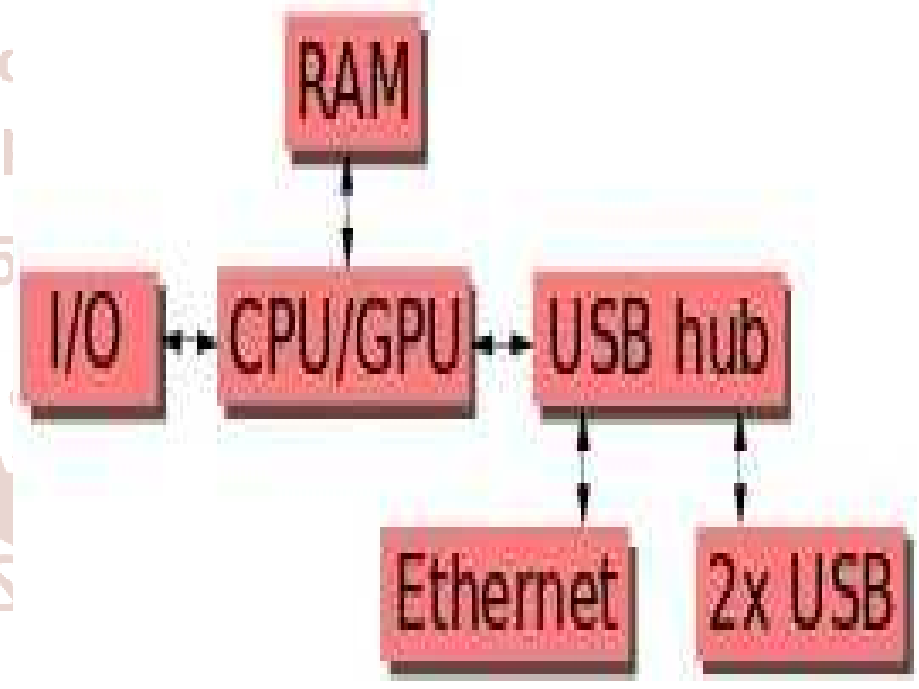

\section{PROBLEM DEFINITION}

The security is the prime concern and implementing security essentials through image processing is a challenging and most acceptable approach. My research is based on image cloning means getting desired results after comparing two images. In simple words a very efficient Raspberry Pi based security mechanism that will be based on image processing concept. 


\section{OBJECTIVES}

The main objectives are described as below:

1. To implement a cost effective security system.

2. Can be a very flexible and efficient Steganography based tool.

3. Can be a very flexible image based data backup option.

\section{PROPOSED WORK}

The aim is to make a smart image processing based system that can used for number of circumstances like surveillance system for remote security monitoring, data security in terms of encrypting and decrypting using images, Data backup, IOT based home automation etc. in my approach two Raspberry Pi devices can connected over internet/network. Camera will be fitted on one Raspberry Pi to capture images manually but if we need to capture images automatically based on motion detection, the deployment of PIR Sensor is necessary. The USB Camera captures the images and sends it to the USB port of the Raspberry Pi. After capturing images the images will be transmitted to second Raspberry Pi in encrypted format. The main motive behind using second Raspberry $\mathrm{Pi}$ is only to get the perfect and original results if somehow the image is altered in first Raspberry Pi means a simple data backup option for future use.

\section{METHODOLOGY}

Hardware Synchronization

Camera Attachment

In this step camera is fixed on Raspberry Pi as shown below:

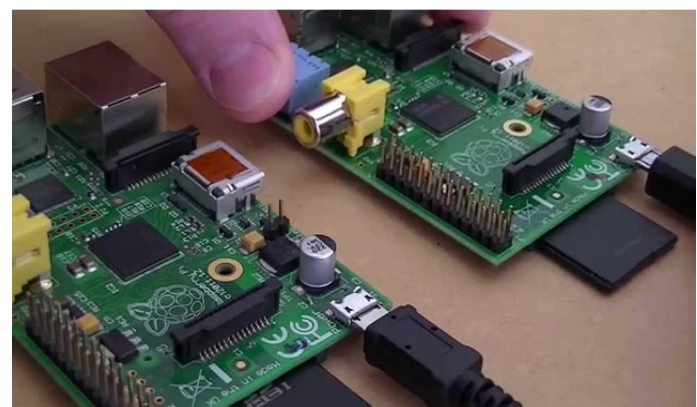

\section{Image Capture}

Image capturing is the main step in my research. In this step the camera fitted one Raspberry Pi capture the images but if we need to capture images on motion detection, the deployment of PIR sensor is a mandatory case.

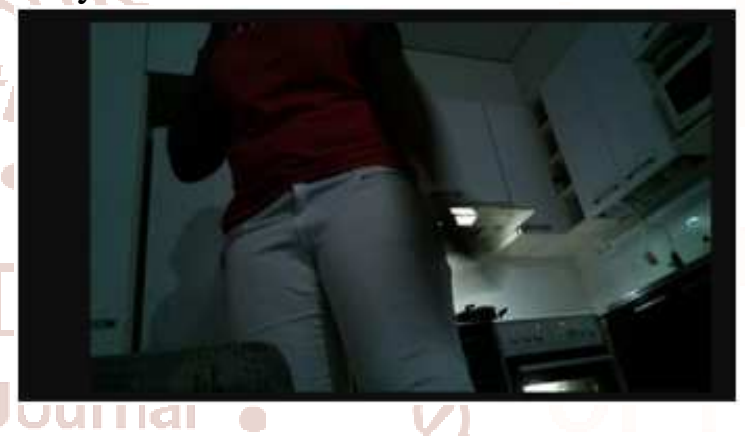

\section{Raspberry Pi Configuration}

The configuration of Raspberry Pi means settings of different options on computer to make device ready for use. The configuration of Raspberry $\mathrm{Pi}$ is described as shown in the following figure.

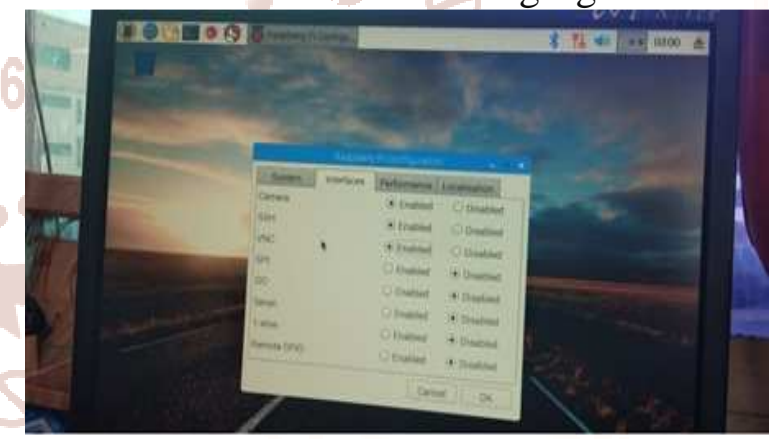

\section{Displaying image:}

In this step the screen is configured with another Raspberry $\mathrm{Pi}$ which displays the clone of captured image in an encrypted format as shown below:

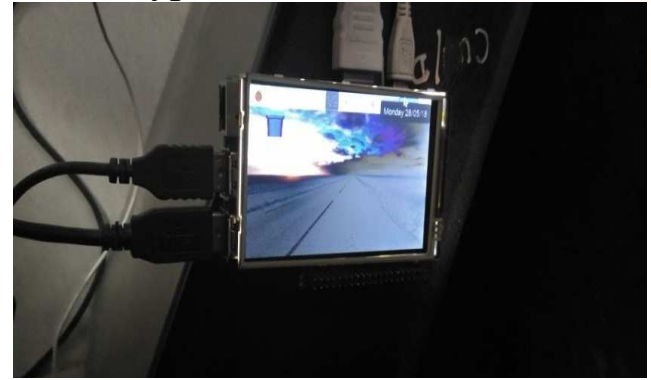

\section{Connecting Raspberry Pi Devices}

The two Raspberry Pi devices can be connected over the internet/network as shown below: 


\section{CONCLUSION:}

Image processing and IOT are the latest and emerging technologies with great impact on modern life. Data security is a very vast domain and implementing data security using image processing is a challenging task. The whole research is based on cost effective and very dynamic security approach using Raspberry Pi concept. Images will be captured through camera fitted on one Raspberry Pi and the copy of the same image will be transmitted to another Raspberry Pi in encrypted format. To get the desired and perfect results the two images will be compared. In simple words a very dynamic steganography based tool for achieving modern security.

\section{REFERENCES:}

1. Hasan M, Hossain E, Niyato D. Random access for machine-to-machine communication in LTEadvanced networks: issues and approaches. IEEE communications Magazine. 2013 Jun;51(6):86-93

2. Prasad S, Mahalakshmi P, Sunder AJ, Swathi R. Smart Surveillance Monitoring System Using Raspberry PI and PIR Sensor. Int. J. Computer. Sci. Inf. Technol. 2014 Jun;5(6):7107-9.

3. IT-CCTV-RP AP. Selection of Cameras, Digital Recording Systems, Digital High-Speed Networks and Train lines for Use in Transit-Related CCTV Systems.

4. Bunting $\mathrm{T}$, inventor. Glass Break Detector. United States patent application US 15/207,501. $2016 \mathrm{Jul}$ 11.

5. Adonailo RS, Li TT, Zakrewski DS, inventors; Honeywell International, Inc., as-signee. False alarm reduction in security systems using weather sensor and control panel logic. United States patent US 7,218,217. 2007 May 15.

6. Albert DE, inventor; Innovalarm Corporation, assignee. Enhanced fire, safety, security and health monitoring and alarm response method, system and device. United States patent US 7,173,525. 2007 Feb 6.

7. Cleary TG, Chernovsky A, Gross handler WL, Anderson M. Particulate entry lag in spot-type smoke detectors. Fire Safety Science. 2000; 6: 779-90.
8. Yavuz So, Taşbaşi A, Evirgen A, Kara A. Motion Detector with PIR sensor us-age areas and advantages.

9. Pretty B. Building a Home Security System with Beagle Bone. Packt Publishing Ltd; 2013 Dec 17.

10. Rodic A, Katie D, Mester G. Ambient intelligent robot-sensor networks for environmental surveillance and remote sensing. In Intelligent Systems and Informatics, 2009. SISY'09. 7th International Symposium on 2009 Sep 25 (pp. 3944). IEEE.

11. DIVE GD. Sensing Impacts: Remote Monitoring using Sensors.

12. Hart-Davis G. Deploying Raspberry Pi in the Classroom. Apress; 2017.

13. Dennis AK. Raspberry Pi Computer Architecture Essentials. Packt Publishing Ltd; 2016 Mar 22.

14. Alee R. Reading data from a digital multi meter using a Raspberry pi.

15. Dhake PS, Borde SS. Embedded Surveillance System Using PIR Sensor. International Journal of Advanced Technology in Engineering and Science. 2014 Mar; 2 (3).

16. Aggarwal S. Principles of remote sensing. Satellite remote sensing and GIS applications in agricultural meteorology. 2004; 23.

17. Cho S, Shin MH, Kim YK, Seo JE, Lee YM, Park $\mathrm{CH}$, Chung JH. Effects of infrared radiation and heat on human skin aging in vivo. In Journal of Investigative Dermatology Symposium Proceedings 2009 Aug 31 (Vol. 14, No. 1, pp. 1519). Elsevier.

18. Chowdhury ZI, Imtiaz MH, Azam MM, Sumi MR, Nur NS. Design and implementation of pyroelectric infrared sensor based security system using microcontroller. In Students' Technology Symposium (Tech Sym), 2011 IEEE 2011 Jan 14 (pp. 1-5). IEEE.

19. Desai G. IoT approach for motion detection using raspberry PI.

20. Nguyen HQ, Loan TT, Mao BD, Huh EN. Low cost real-time system monitoring using Raspberry Pi. In Ubiquitous and Future Networks (ICUFN), 2015 Seventh International Conference on 2015 Jul 7 (pp. 857-859). IEEE. 